\title{
ENTRE A DANAÇÃO E A GLÓRIA: O MINISTÉRIO DE FLORDELIS E O PROBLEMA DA OIKONOMIA CRISTÁ ${ }^{1}$
}

Mariana Côrtes ${ }^{2}$

Resumo: O presente texto estabelece um diálogo com o artigo "Fazendo política em outros Congressos: tramas religiosas, práticas midiáticas e a estética da política nas periferias urbanas do Rio de Janeiro" de Carly Machado. As práticas missionárias realizadas pelo Ministério Flordelis implodiram as fronteiras da "igreja", pois as dinâmicas pentecostais da regiấo metropolitana do Rio de janeiro operadas em torno das categorias "ministérios" e "congressos" ultrapassam o lócus doutrinal e institucional da denominação. Este texto apresenta a hipótese de que o uso das noções de "ministério" e "congresso" não representa uma apropriação do político pelo religioso, mas indica exatamente o oposto. Eles são termos da esfera política que revelam uma "assinatura", conceitos que se apresentam de forma "secularizada", mas que carregam o segredo do seu pertencimento à esfera teológica, na forma de uma oikonomia cristã.

Palavras-chave: Pentecostalismo; Ministério; Congresso; Esfera teológica.

\section{BETWEEN DAMNATION AND GLORY: FLORDELIS MINISTRY AND THE PROBLEM OF CHRISTIAN OIKONOMIA}

\begin{abstract}
The following text establishes a dialogue with the article "The making politics in other Congresses: religious entanglements, media practices and the aesthetics of politics in the urban peripheries of Rio de Janeiro" by Carly Machado. The missionary practices carried out by the Flordelis Ministry imploded the "church" borders since Pentecostal dynamics of the metropolitan region of Rio de Janeiro

${ }^{1}$ Como citar: CÔRTES, Mariana. Entre a danação e a glória: o ministério de Flordelis e o problema da Oikonomia cristá. Debates do NER, Porto Alegre, v. 2, n. 38, p. 83 $-95,2020$.

${ }^{2}$ Doutora em Ciências Sociais pela Universidade Estadual de Campinas, Brasil. Professora de Sociologia do Instituto de Ciências Sociais da Universidade Federal de Uberlândia, Brasil. E-mail: marianampcortes@gmail.com.
\end{abstract}


operate around the categories of "ministry" or "congress", and by doing so, they go beyond the doctrinal and institutional locus of the "denomination". This text presents the hypothesis that the use of notions such as "ministry" or "congress" does not represent an appropriation of the political by the religious, but indicates the exact opposite. They are terms of the political sphere that reveal a "signature", concepts that present themselves in a secularized way, but carry the secret of their belonging to the theological sphere, in the form of a Christian oikonomia.

Keywords: Pentecostalism; Ministry; Congress; Theological sphere.

O artigo "Fazendo política em outros Congressos: tramas religiosas, práticas midiáticas e a estética da política nas periferias urbanas do Rio de Janeiro" de Carly Barboza Machado se propõe a pensar a relação entre pentecostalismo, mídia e política a partir de um evento que acontece há mais de uma década no município de São Gonçalo, Rio de Janeiro: o Congresso Internacional de Missóes - CIM, promovido pelo Ministério Flordelis. Leva o nome da pastora evangélica, cantora gospel e deputada federal responsável por condensar em torno de si uma série de práticas estratégicas e governanças pentecostais no contexto das periferias urbanas fluminenses. Flordelis foi objeto de uma controvérsia recente quando se tornou, em agosto de 2020, a principal suspeita de ser a mandante do assassinato de seu marido, o Pastor Anderson do Carmo, morto em junho de 2019. A exposição midiática do caso nos principais canais de televisão e a produção maníaca de memes que ridicularizavam a personagem de Flordelis inscreviam com o signo da infâmia essa mulher negra, de origem pobre e periférica, que havia, segundo a acusação judicial, planejado de forma atroz o homicídio do próprio marido, com a suposta colaboração de dois dos seus filhos, dos cinquenta e cinco, quatro biológicos e cinquenta e um adotados. A partir do escândalo do assassinato do marido, a mancha da ignomínia, depositava-se sobre Flordelis como uma profecia autorrealizada. Afinal, sua trajetória de mulher negra, nascida e criada na favela do Jacarezinho, Zona Norte da cidade do Rio de Janeiro, marcada, em 
sua narrativa de superação, pela luta contra bandidos e juízes pela guarda dos seus filhos, arrancados de situaçôes de violência e experiências na criminalidade, condensava um percurso biográfico "manco", "bastardo" e "ambíguo" (Bourdieu, 1999). Flordelis ocupava uma zona cinzenta de indecidibilidade, que a fazia deslizar, nas representaçôes veiculadas pelos meios de comunicação de massa, "ora como louca, ora como heroína” (Machado, 2020), ora como aquela que havia sequestrado meninos e meninas que não eram oficialmente seus filhos, ora como aquela que havia salvado crianças dos horrores do mundo do crime. Assim, o interessante artigo de Carly Machado (2020) nos faz entrever que quando a acusação do planejamento do assassinato do próprio marido passa a pairar sobre a imagem de Flordelis, ela não redunda no vazio, mas passa a ocupar um território de suspeição previamente estabelecido, em torno de uma figura cuja imagem já oscilava entre a "queda" e a "redenção", o "escândalo" e a "vitória", a "blasfêmia" e a "verdade" (Machado, 2020).

Sob a experiência ambivalente de quem habita um espaço liminar entre a desgraça e o livramento, Flordelis construiu seu trabalho como missionária nas favelas cariocas desde a década de 1990. A partir de 2002, o Ministério Flordelis passa a atuar na cidade de Sáo Gonçalo, onde o Congresso Internacional de Missóes - CIM começa a se realizar periodicamente. Machado (2020) desenvolveu sua pesquisa empírica sobre o Congresso entre os anos de 2016 a 2018, na Cidade do Fogo - nome da sede do Ministério Flordelis, acompanhando os processos que levam à sua preparação, organização e montagem, incluindo a intensa mobilização das redes sociais, que anunciavam a presença de convidados cujo capital simbólico no campo pentecostal atestavam a capacidade de agenciamento de Flordelis na articulação de atores importantes no movimento pentecostal, como representantes da indústria fonográfica gospel e sujeitos ligados à política local e nacional. O trabalho de Carly Machado (2020), ao investigar a relação entre pentecostalismo, mídia e política a partir de um evento na região metropolitana do Rio de janeiro, se situa na linhagem de uma série de estudos que passaram a compreender a atuação de igrejas, ministérios, eventos, projetos sociais, comunidades terapêuticas pentecostais nas periferias das metrópoles e cidades médias brasileiras como a formação de um novo regime de condução 
das condutas dos sujeitos habitantes das margens (Birman, 2003; Mafra, 2011; Vital da Cunha, 2015; Teixeira, 2016; Côrtes, 2017; Sant'Ana, 2017). Em seu artigo "O problema da formação do 'cinturão pentecostal' em uma metrópole da América do Sul", Clara Mafra (2011) mostra como parte das metrópoles latino-americanas ingressaram no século XXI como uma "configuração urbana peculiar", que ela denominou de "cinturão pentecostal". Em torno das regióes centrais, consolidadas e históricas das metrópoles, de maioria católica, configurou-se um cinturão periférico, formado por bairros, subúrbios e cidades com condiçôes urbanas precárias e uma presença significativa de pentecostais. $\mathrm{Na}$ etnografia realizada por Mafra (2011) na região metropolitana do Rio de Janeiro, a autora observou que os sujeitos periféricos, distantes das contrapartidas de prestação e contraprestação de "favores" que concertavam, de forma tradicional, a relação interclasse entre ricos e pobres sob o modelo católico de regulação das mediaçôes sociais, rompiam com essas modalidades de subordinação, percebidas sob o signo da humilhação e passavam a construir formas emergentes de relações intraclasse. Nessas relaçóes, as diferenças sociais passam a ser dramatizadas segundo novos critérios, como a disputa interna entre fiéis em torno de qualificaçóes carismaticamente orientandas, por exemplo, a atribuição de quem "é mais ungido" ou "tem mais intimidade com o Espírito Santo" (Mafra, 2011). Em trabalho anterior sobre a atuação da Assembleia de Deus dos Últimos Dias (Adud), com sede em São João de Meriti, Baixada Fluminense do Rio de Janeiro, Machado (2014) analisou a formação de um complexo dispositivo do sofrimento a partir da investigação sobre os testemunhos dos "resgatados da morte", homens que haviam experimentado a criminalidade violenta e reconfiguraram sua narrativa de vida a partir da "figura potente" do resgatado. A fabricação de uma nova mediação intraclasse (Mafra, 2011) e a recusa da humilhação ofereceram as condiçôes sociais para a criação de um dispositivo do sofrimento que, sob relaçôes intraclasse, também recusava a subserviência e contornava a "vitimização" (Machado, 2014). Assim, o "cinturão pentecostal" produzia agenciamentos inventivos para lidar com as condiçôes de precariedade/ vulnerabilidade/violência das periferias, ao mesmo passo que criava novos modos de subjetivação dos adeptos do pentecostalismo. 
Durante a década de 1990, diante da perplexidade do impacto do crescimento evangélico em um país onde o catolicismo detinha a hegemonia quase absoluta do mercado de ofertas de bens de salvação, parte dos pesquisadores brasileiros elaboraram o seguinte diagnóstico: a remagificação do religioso, a democratização do êxtase e a exacerbação do emocional eram sintomas do atraso brasileiro, próprio de uma sociedade que não havia levado o processo de secularização às últimas consequências (Prandi \& Pierucci, 1996). A partir dos anos 2000, os estudos das ciências sociais brasileiras sobre o pentecostalismo, contudo, passam por uma inflexão epistemológica, teórica e empírica. O problema do projeto inacabado da secularização sai de cena para a chegada da constataçáo de que o que estava acontecendo nas periferias brasileiras não podia ser simplesmente descrito como a formação de um "pronto-socorro mágico" para desesperados, sinal inequívoco de nossa inoperância civilizacional. O que estava em jogo era outra coisa, ainda inaudita, que precisava ser investigada. Os trabalhos de Carly Machado sobre as práticas da Assembleia de Deus dos Últimos dias (Adud) no resgate de criminosos (2014), a operação das comunidades terapêuticas pentecostais na recuperação de "viciados" em drogas (2020, no prelo), e mais recentemente, a produçáo do evento midiático-massivo do Congresso Internacional de Missóes do Ministérios Flordelis (2020), nos permitem vislumbrar que, nas periferias das cidades brasileiras, particularmente do Rio de Janeiro, foco das etnografias da pesquisadora, estão sendo gestadas tecnologias sociais altamente criativas de condução das condutas dos indivíduos, em que o governo do outro só é possível a partir de um governo sobre si. Nesse processo, os sujeitos periféricos são, ao mesmo tempo, sujeitos e objetos dessa condução, em uma forma de governo que só é possível a partir da potência de agência dos governados: a capacidade de reformular seus lugares sociais de classe/gênero/raça; de rejeitar a humilhação social e recompor sua própria identidade; de fabricar uma narrativa de vida em torno da experiência incessantemente repetida do sofrimento (Machado, 2014); de permear "rotas de fuga" dos "exílios" urbanos cotidianamente vivenciados pelos habitantes das margens (Machado, 2020, no prelo); de compor sua história em torno do "tempo do suplício" (Machado, 2020) da degradaçáo social, moral e afetiva, e sua possibilidade infinitamente 
construída da espera do "tempo da redenção". Como entrevemos na trajetória de Flordelis: "Olham para mim, já julgando meu final; Esquecendo que o meu Deus, é um Deus sobrenatural; O Deus que dá valor, a quem o mundo humilhou; é o Deus que virada em minha vida decretou". No hino "A volta por cima", cantado de forma pungente e sôfrega por Flordelis, vislumbramos, como argumenta Machado, que "a partir do escândalo da morte de Anderson do Carmo, ela própria encarnou o suplício de redefinir sua história”.

Em seu artigo, Carly Machado (2020) mostra que para compreender o Ministério Flordelis é preciso investigar o "conglomerado denso formado por instituiçóes religiosas, do mercado e político partidárias”, que ultrapassam os limites do que poderíamos denominar como "templo" ou "igreja”, que circunscreveu, por muito tempo, os esforços heurísticos e as incursões empíricas dos estudos sobre o pentecostalismo no Brasil. Max Weber (1982) afirmou que a formação de uma "congregação soteriológica de fiéis" nas religiôes de salvação acontece por meio de um corte disruptivo com o chamado "clã natural". O profeta convoca seus seguidores a abandonar "os seus" para fundar uma comunidade exclusivamente religiosa, em que os "irmãos de fé" devem predominar sobre os "irmáos de sangue". Na convocaçáo profética originária do cristianismo, "os que não podem ser hostis aos membros da casa, ao pai e à mãe, não podem ser discípulos de Jesus” (Weber, 1982, p. 377). A religião profética para Weber (1982), como argumenta Pierucci (2006), tem como modus operandi não a reposição da ordem, mas a ruptura com o status quo, em sua dimensão propriamente solvente de laços estabelecidos a fim de criar laços inteiramente novos, "para a invenção de uma vida comunitária nova, buscada, experimentada e escolhida pelo 'indivíduo-agora-individuado' que se disponibilizou a deixar-se levar por um chamado, um convite, um anúncio" (Pierucci, 2006, p. 122). Após a interpelação profética que destrói, sem culpa nem pejo, as conexóes sagradas mediadas pelo sangue, para inventar, ex nibilo, uma congregação inédita, a administração dos adeptos arrancados dos seus pertencimentos originários, deve ficar a cargo do sacerdote, que, no processo de rotinização do carisma, desempenhará o exercício cotidiano de "cura de almas", ou seja, o trabalho de reprodução do dogma bem como o de escuta, aconselhamento e condução da vida dos fiéis 
(Weber, 1982). O modelo conceitual da "congregação", do "templo" ou da "igreja”, sistematizado por Weber e outros autores importantes dos estudos da religião, constituiu-se, dessa forma, como um "privilégio teórico", que pode ter contribuído para invisibilizar outras configuraçôes religiosas que não podem ser limitadas ao espaço das denominaçóes pentecostais, onde se atualizam as liturgias, os ritos e os cultos cotidianos.

O trabalho de Machado (2020) mostra que, nas dinâmicas pentecostais da região metropolitana do Rio de Janeiro, as fronteiras do "templo" foram implodidas, pois as açóes religiosas que são operadas em torno da categoria "ministérios" ultrapassam o lócus da denominação. No caso do Ministério Flordelis, argumenta Machado (2020), é o projeto missionário - e não o espaço institucional, burocratizado e doutrinal da igreja - que oferece o fundamento para todas as iniciativas de evangelização: “a ação religiosa é o Ministério”. Seu ministério é a "expansão de um ministério pessoal (cuidar de jovens), de louvor (carreira musical) e sua fama (presença midiática)”. A pesquisadora propóe então que a ideia de "ministério" pode ser pensada como uma possível categoria analítica, que tem "como característica principal seus projetos voltados para a vida no mundo, na cidade, nas casas, nas famílias, nas ruas, e por isso nos ajudam a pensar a relação entre o religioso, o ordinário e o espaço público". Assim, Carly Machado nos propóe uma investigação heurística sensível para a “dimensão dinâmica e multiplicadora” não só dos ministérios, mas também dos inúmeros congressos e eventos pentecostais. Convida-nos a compreender que a forma de condução pentecostal das condutas dos habitantes das margens também passa por uma tecnologia de governo que não é só a do templo, mas também um engajamento aberto no tempo e no espaço, uma interpelação que supóe a agência criativa dos sujeitos nas atividades missionárias desterritorializadas e mutáveis, incessantemente amplificadas pelas estratégias midiáticas e pelas redes sociais. Machado (2020) nos oferece, portanto, um achado analítico instigante para pensar quais são os modos de operação dos "ministérios" e "congressos", e também para interrogar o porquê de essas categorias habitarem tanto o mundo religioso como o mundo político, deixando uma brecha para a suspeita de que essa homologia indicada pela autora não seja mera coincidência. Talvez, o uso 
das noçôes de "ministério" e "congresso" não sejam apropriações do político pelo religioso, mas indiquem exatamente o oposto: "ministério" e "congresso" são termos da esfera política institucional que denunciam uma "assinatura", ou seja, um conceito que se apresenta na sociedade moderna de forma "secularizada", e que carrega em si mesmo o segredo do seu pertencimento passado à esfera teológica (Agamben, 2011).

Em seu livro "O reino e a glória: Uma genealogia teológica da economia e do governo", o filósofo italiano Giorgio Agamben (2011) apresenta a tese de que da teologia cristã derivam dois paradigmas políticos opostos e complementares:

a teologia política, que fundamenta no único Deus a transcendência do poder soberano, e a teologia econômica, que substitui aquela pela ideia de uma oikonomia, concebida como uma ordem imanente - doméstica e náo política em sentido estrito - tanto da vida divina quanto da vida humana (Agamben, 2011, p. 13).

Se, de um lado, a ideia de que o paradigma do monoteísmo cristão tenha oferecido o fundamento para a teoria moderna da soberania, não seja em si mesma uma novidade teórica, a hipótese de Agamben se torna particularmente interessante quando percebemos que a gênese do liberalismo do século XVIII - e seu correlato, a biopolítica como forma de governamentalidade (Foucault, 2008a; 2008b) - se encontra em uma formulação, até então insuspeitada, da própria teologia cristâ: a ideia de uma oikonomia como governo divino do mundo. A filosofia clássica aristotélica opunha como duas esferas absolutamente separadas o oikos e a polis, sendo o primeiro um organismo complexo que representa a esfera doméstica, no qual se entrelaçam relaçóes despóticas senhores-escravos, relaçóes pais-filhos e relaçóes conjugais; e a polis, espaço da política propriamente dita, onde os cidadãos discutem sobre os bens da cidade e exercitam sua capacidade de logos, qual seja, a reflexão sobre a distinção entre o justo e o injusto, o belo e feio, o verdadeiro e o falso (Agamben, 2002). A polis só seria possível na condição de exclusão do oikos do mundo da política, o que implica na distinção entre a vida politicamente qualificada (bios) e a vida como condição puramente animal (zoê). Nos primeiros séculos da era cristã, entre o II 
e IV, observa-se um "desenvolvimento imponente" da teologia cristá que passa a produzir um deslizamento semântico da noção de oikonomia para o âmbito teológico, concebendo a comunidade messiânica, de saída, não nos termos de uma política, mas de uma oikonomia. Nela, o ser vivo, criado à imagem de Deus, foi desde o início capaz unicamente de realizar a vida como zoé, e não como bios; em outros termos, nunca se revelou capaz de uma política, mas apenas de uma economia. Assim, para Agamben, o fato de que, "em última instância a história seja um problema não político, mas 'gerencial' e 'governamental', não é, nessa perspectiva senão uma consequência lógica da teologia econômica” (2011, p. 15).

Não deixa de ser interessante, e ao mesmo tempo perturbador, revisitar agora o Ministério Flordelis, analisado por Machado (2020), a partir dessa provocação desconcertante de Agamben (2011). Afinal, na trajetória de mãe biológica e adotiva de cinquenta e cinco filhos, pregadora pentecostal, cantora gospel e deputada federal, de Flordelis, o paradigma "gestionário", "administrativo" e "governamental” parece cruzar instâncias supostamente diferentes - e, por vezes, antinômicas. Seu ministério atravessa a gestão da sua própria casa, dos seus filhos, das igrejas, das ruas, das favelas, dos subúrbios, das cidades, dos eventos pentecostais, da carreira musical e midiática, do empreendimento político como deputada federal, até chegar no Congresso Nacional. A gestão de uma instância se replica, se estende e se expande na gestão de outra, em uma zona de indiscernibilidade entre o que é próprio da esfera da casa e o que é próprio da esfera da política, em que o econômico e o político "entram em relação de recíproca contaminação" (Agamben, 2011, p. 38), tornando inoperante a oposição entre oikos e polis. Cuidar dos filhos e zelar pelos eleitores na Câmara dos Deputados faz parte de um mesmo empreendimento gerencial. O seu ministério é, portanto, essa ação perpétua de governo que, contudo, torna-se uma máquina incessante que opera no vácuo, pois o dispositivo econômico, demonstrado por Agamben (2011), é um dispositivo que gira em torno de si mesmo, cujo centro está vazio.

Para Agamben (2011), o centro do dispositivo governamental está vazio porque a teologia cristá é marcada por uma fratura entre Deus e sua ação, entre ontologia e práxis, pois, de um lado, tem-se a substância de Deus que deve ser eternamente igual a si mesma, e de outro, tem-se o problema do governo 
divino do mundo, que se encontra no plano da oikonomia, ou seja, no plano da administração da natureza e dos homens. A teologia cristã se divide então em uma máquina bipolar que cinde para sempre a dimensão ontológica e não ativa de Deus e a dimensão econômica e ativa de Deus. "A fratura entre teologia e oikonomia, entre ser e ação, na medida em que torna livre e 'anárquica' a práxis, estabelece ao mesmo tempo a possibilidade e a necessidade de seu governo" (Agamben, 2011, p. 81). Ao tornar a práxis divina "anárquica", ou seja, sem arché, desprovida de origem e fundamento, baseada em uma vontade triunfante e onipotente de Deus, mas carente de substância, torna-se imperativo, de forma paradoxal, que haja um governo. A questáo teológica que se coloca é: como conciliar a providência de Deus e seu governo do mundo com o livre-arbítrio dos homens? A resposta teológica a esse problema é surpreendente: Deus governa o mundo como se tivesse ausente dele, como se as criaturas governassem livremente a si mesmas. A providência náo pode ser simplesmente um ato de violência, mas deve operar através da própria natureza dos homens. Temos aí, de forma inusitada, a genealogia da arte de governar liberal, cujo governo dos outros só é possível a partir da agência dos governados. Os dispositivos de segurança, descritos por Foucault (2008a; 2008b), operam a partir da natureza das coisas, na gestấo das variáveis que intervêm no jogo social.

Os ministerios, em sua "dinâmica expansiva e multiplicadora", analisados por Machado (2020), são dispositivos pentecostais de governo altamente inventivos, em que as fronteiras entre o governo do outro e o governo de si se esfumam. A prédica do/a pastor/a, o louvor do/a cantor/a, o testemunho do/a missionário/a, rebatem nas experiências de vida dos fiéis, que constroem, por eles mesmos, suas próprias narrativas de recaídas e livramentos, tormentos e bênçăos, num campo aberto que se amplia nos eventos, nas mídias, nas redes sociais. Os ministérios e os congressos pentecostais não adquirem esse nome por um acaso fortuito, mas constituem um segredo escondido - a assinatura teológica dos ministérios e congressos da democracia liberal moderna. Não é por acaso, portanto, os vários agentes do campo pentecostal, que ingressaram nas últimas décadas no campo da política institucional, possam transitar de uma esfera para a outra com uma certa facilidade, pois, como é o caso de Flordelis, sua identidade de 
mãe, sua carreira como pastora, seu trabalho como deputada são expedientes que partilham de uma premissa comum: o dispositivo "gerencial" da oikonomia.

Segundo Agamben (2011), a reflexão política moderna está capturada em um equívoco: ao se concentrar em "abstraçóes e mitologemas vazios como a Lei, a vontade geral e a soberania popular” (2011, p. 299), deixou escapar o problema político realmente relevante. Para o autor,

O verdadeiro problema, o arcano central da política, não é a soberania, mas o governo, não é Deus, mas o anjo, não é o rei, mas o ministro, não é a lei, mas a polícia - ou seja, a máquina governamental que eles formam e mantêm em movimento" (Agamben, 2011, p. 299).

Quando a instigante pesquisa de Carly Machado se propóe a investigar "os modos de formação e ação política no campo pentecostal", a partir das categorias analíticas dos ministérios e congressos, uma chave teórica se abre para os estudos que se ocupam do pentecostalismo, mídia e política no Brasil contemporâneo. As intricadas tramas que articulam a governança pentecostal nas periferias e a ocupação de postos na política institucional, que a pesquisa de Machado (2020) pretende iluminar, é um dos desafios heurísticos mais importantes que se colocam atualmente para as ciências sociais brasileiras. Pretendi, neste texto-comentário, trazer para o debate a instigante reflexão de Giorgio Agamben (2011), pois ela inverte os termos com que às vezes a discussão é colocada: o problema é menos a ameaça à laicidade do Estado no Brasil e mais o quanto o próprio processo - sempre ininterrupto - de governamentalização do Estado só pode ser compreendido a partir dos dispositivos pentecostais de governo que, partindo das margens, contribuem para compor o modus operandi do governo brasileiro. E, se os dispositivos pentecostais de governo conhecem uma relativa eficácia quando atuam no centro da máquina estatal, é justamente porque partilham de uma mesma oikonomia originária, em que o interessante não é o poder legislativo, mas o poder executivo; não é o problema da lei, mas o problema da operação; 
não é a questão da transcendência de Deus, mas como os homens devem ser guiados, conduzidos, orientados, no espaço liminar entre a danação e a glória.

\section{REFERENNCIAS}

AGAMBEN, Giorgio. Homo sacer: O poder soberano e a vida nua I. Belo Horizonte: Editora UFMG/Humanitas, 2002.

AGAMBEN, Giorgio. O reino e a glória: Uma genealogia teológica da economia e do governo. Homo sacer, II, 2. São Paulo: Boitempo, 2011.

CÔRTES, Mariana. Diabo e fluoxetina: Pentecostalismo e psiquiatria na gestão da diferença. Curitiba: Appris, 2017.

BIRMAN, Patricia (org). Religião e espaço público. São Paulo: Attar Editorial, 2003.

BOURDIEU, Pierre. A economia das trocas simbólicas. São Paulo: Perspectiva, 1999.

FOUCAULT, Michel. Segurança, território, população. São Paulo: Martins Fontes, 2008a.

FOUCAULT, Michel. Nascimento da biopolítica. São Paulo: Martins Fontes, 2008b.

MACHADO, Carly Barboza. Pentecostalismo e o sofrimento do (ex-) bandido: testemunhos, mediações, modos de subjetivação e projetos de cidadania nas periferias. Horizontes antropológicos, n. 42, dezembro de 2014, pp. 153-180.

MACHADO, Carly Barboza. Fazendo política em outros Congressos: tramas religiosas, práticas midiáticas e a estética da política nas periferias urbanas do Rio de Janeiro. Debates do NER, Porto Alegre, v. 2, n.38, 2020. MACHADO, Carly Barboza. Presos do lado de fora: comunidades terapêuticas como zonas de exilio urbano (artigo no prelo). 2020. 
MAFRA, Clara. O problema da formação do "cinturão pentecostal" em uma metrópole da América do Sul. Revista Interseçóes, Rio de Janeiro, v. 13, jun. 2011, p. 136-152.

PIERUCCI, Flávio. A religião como solvente - Uma aula. Novos Estudos Cebrap, no. 75, São Paulo, julho de 2006.

PRANDI, Reginaldo; PIERUCCI, Flávio. A realidade social das religióes no Brasil. São Paulo: HUCITEC, 1996.

SANT'ANA, Raquel. A Nação cujo Deus é o Senhor: a imaginação de uma coletividade "evangélica" a partir da Marcha para Jesus. Tese (doutorado em antropologia social), Museu Nacional, Universidade Federal do Rio de Janeiro, Rio de Janeiro, 2017.

TEIXEIRA, Jacqueline Moraes. A mulher Universal: corpo, gênero e pedagogia da prosperidade. Rio de Janeiro: Mar de Idéias, 2016.

VITAL da Cunha, Christina. Oração de traficante: Uma etnografia. Rio de Janeiro: Garamond, 2015.

WEBER, Max. Ensaios de Sociologia. Rio de Janeiro: Guanabara Koogan S. A., 1982.

Recebido em: 03/11/2020

Aprovado em: 03/11/2020 
